\title{
Review Article \\ The Role of the Endothelin System in the Vascular Dysregulation Involved in Retinitis Pigmentosa
}

\author{
Francesco Saverio Sorrentino, ${ }^{1}$ Claudio Bonifazzi, ${ }^{2}$ and Paolo Perri ${ }^{3}$ \\ ${ }^{1}$ Department of Surgical Sciences, Unit of Ophthalmology, Ospedale Maggiore, Bologna, Italy \\ ${ }^{2}$ Department of Biomedical and Surgical Sciences, Section of Human Physiology, University of Ferrara, 44100 Ferrara, Italy \\ ${ }^{3}$ Department of Biomedical and Surgical Sciences, Division of Ophthalmology, University of Ferrara, 44100 Ferrara, Italy
}

Correspondence should be addressed to Francesco Saverio Sorrentino; fra.sorrentino@gmail.com

Received 23 August 2015; Accepted 18 October 2015

Academic Editor: Suphi Taneri

Copyright (c) 2015 Francesco Saverio Sorrentino et al. This is an open access article distributed under the Creative Commons Attribution License, which permits unrestricted use, distribution, and reproduction in any medium, provided the original work is properly cited.

Retinitis pigmentosa is a clinical and genetic group of inherited retinal disorders characterized by alterations of photoreceptors and retinal pigment epithelium leading to a progressive concentric visual field restriction, which may bring about severe central vision impairment. Haemodynamic studies in patients with retinitis pigmentosa have demonstrated ocular blood flow abnormalities both in retina-choroidal and in retroocular vascular system. Moreover, several investigations have studied the augmentation of endothelin-1 plasma levels systemically in the body and locally in the eye. This might account for vasoconstriction and ischemia, typical in vascular dysregulation syndrome, which can be considered an important factor of reduction of the ocular blood flow in subjects affected by retinitis pigmentosa.

\section{Introduction}

Recent studies have observed the reduced blood flow in both ocular and peripheral districts in patients suffering from retinitis pigmentosa (RP) [1]. The drop of the blood flow has been detected not only in retinal and choroidal vessels but also in retroocular vessels [2-4]. Also, a reduced baseline peak flow in the cutaneous capillary of fingers has been measured and a significantly longer recovery time has been found after cold provocation [4]. In the early stages of RP before detecting any ophthalmoscopic fundus modification, an increase of the arteriovenous passage time has been observed in the retina [5]. Using colour Doppler imaging, Cellini and coworkers demonstrated reduced peak systolic velocities in both ophthalmic arteries and posterior ciliary arteries [3,4]. They also observed a certain augmentation of endothelin-1 (ET-1) plasma levels in patients with earlystage RP, even though some investigators took issue with this observation [6-8].

A sort of dysregulation of both blood supply and vessel caliber seems to occur often in RP patients. Konieczka has suggested that the primary vascular dysregulation syndrome, mainly characterized by an impaired vascular tone, might describe a wide range of local and systemic signs, such as ocular blood flow reduction with subsequent augmentation of ET-1 plasma levels in the eye and peripheral vasospasm in response to cold, emotional stress, or low blood pressure [1, 9-13]. Disturbed autoregulation of ocular perfusion provokes an irregular blood flow, which means an unstable retinal blood supply, and a sort of attenuation of retinal vessels with reduced neurovascular coupling $[14,15]$. Consequently, both free radicals and oxidative stress substantially increase. Therefore, a large number of RP patients show a high prevalence of primary vascular dysregulation syndrome as the primary manifestation of ocular blood flow dysfunction [1]. Even if the exact pathophysiological mechanism is still unknown, the dysfunction of both autonomic nervous system and endothelial cells is currently investigated.

\section{A Brief Overview of Retinitis Pigmentosa}

$\mathrm{RP}$ is a clinical and genetic group of inherited retinal disorders. It is characterized by alterations of photoreceptors (PRs) 
and retinal pigment epithelium (RPE) resulting in progressive retinal degeneration. The most frequent symptoms are nightblindness and the growing impairment of visual field, perceived as tunnel vision, that may lead to legal blindness. Clinical signs found at ophthalmic fundus examination are characteristic: "bone-spicule" pigment deposits in the mid periphery along with RPE atrophy, attenuation of retinal vessels, waxy pallor of the optic disc, and relatively spared macula surrounded by a perimacular ring of depigmentation $[16,17]$.

The age of onset, the rate of progression, and the severity of RP are extremely variable depending not only on the genetic background but also on some influencing factors. Symptoms may start in childhood as well as in the early or mid-adulthood. Even though the progression of the disease is unpredictable, severe visual impairment typically occurs by the age of about $40-50$ years. The prevalence of all different forms of RP is reported to be about 1:3500-5000 individuals and, nowadays, it is estimated that there are almost two million affected people around the world [18, 19].

The group of RP is characterized by a complex association between tremendous genotypic multiplicity and great phenotypic heterogeneity. The severity of the clinical manifestation depends on the penetrance of the disease gene, but also interactions between the gene expression and the environmental factors are of great importance [20].

\section{The Ocular Blood Flow}

The blood flow in the body is fine-tuned both systemically and locally. Specific biochemical and molecular signaling pathways keep monitoring the perfusion pressure, originally controlled by the heart pump, and the local resistances, depending on the vessel caliber. Vasospasm stands for inappropriate constriction of an artery [21]. In the presence of excessive vasoconstriction and/or altered vasodilation, the overall condition is described as vascular dysregulation and it is often accompanied by a barrier dysfunction. If this condition is associated with symptoms or signs, it is referred to as vascular dysregulation syndrome. It can affect any district in the body but mostly the eye [22].

The diameter of the vessels is regulated by contraction (vasoconstriction) or relaxation (vasodilation) of both smooth muscle cells, forming the arterial or venous wall, and pericytes, encircling the capillaries. The smooth muscle cells are very sensitive to modifications of tension (myogenic regulation), numerous metabolic factors originating from surrounding tissues, and biochemical signals coming from the autonomic nervous system (neurohumoral regulation) [23]. The local perfusion pressure, depending on the cardiac output, and the local resistance to flow, depending on the rate of local autoregulation, are the two main aspects of the tissue blood flow.

The endothelium is a very thin layer of cells lining vessels inwards. Beyond its function as mechanical barrier, it plays crucial roles in immune and inflammatory responses, in haemostasis, and in vascular tone regulation. Also it has autocrine, paracrine, and endocrine functions [24, 25].
Two vascular systems supply the eye: the choroidal and the retinal system. The first supplies the iris, the ciliary body, the choroid, and also, by diffusion, the outer retina, including the photoreceptors. The second entirely supplies the inner retina, comprising the retinal ganglion cells. The retinal vascular network is characterized by low perfusion rate, high vascular resistance, and high oxygen extraction. Conversely, the choroidal network shows a high perfusion rate, a low vascular resistance, and a low oxygen extraction. Just similar to the brain circulation, the ocular circulation is autoregulated. Autoregulation, actually effective within certain limits of perfusion pressure, is the intrinsic capacity to maintain constant flow despite changes in perfusion pressure [26].

The neurovascular coupling is the tight link between the caliber of retinal vessels and the neuroretinal activity. A signal from the central nervous system, closely connected to the retina, is able to evoke small changes in the retinal blood flow through complex pathways involving neurons, glia, and endothelial cells. Furthermore, the retinal vascular system features the blood retinal barrier which regulates the flux of ions, proteins, hormones, and water, even monitoring the infiltration of immune competent cells [22]. The choroidal vascular system is richly innervated [27]. It provides oxygen and other metabolites, controls eye temperature, and mostly contributes to the fine-tuning of accommodation by regulating choroidal thickness. This network, featuring fenestrated capillaries, is just partially autoregulated [22].

\section{The Endothelin System}

The endothelin (ET) system encompasses three active peptides (ET-1, ET-2, and ET-3), two G protein-coupled receptors $\left(\mathrm{ET}_{\mathrm{A}}\right.$ and $\left.\mathrm{ET}_{\mathrm{B}}\right)$, and activating peptidases including the ETconverting enzymes (ECE-1 and ECE-2), [28]. Knock-out mice have been used as models to study pathophysiological role of the ET system. Some ET components are essential for the development of both tissues, such as cardiac or craniofacial tissue, and systems, such as enteric and nervous system [29-31]. Endothelin-1 (ET-1), widely distributed in human tissues, is produced by vascular endothelial cells and also by many other cells. Endothelin-2 (ET-2), with equally high affinities for both $\mathrm{ET}_{\mathrm{A}}$ and $\mathrm{ET}_{\mathrm{B}}$, is largely expressed in the gastrointestinal tract and it serves as local and paracrine/autocrine mediator [32]. Very little is known about the function of endothelin-3 (ET-3), except for the fact that it seems to be secreted somewhere near the relevant target cells, such as enteric neuroblasts expressing the $\mathrm{ET}_{\mathrm{B}}$ [33].

First identified in 1988, ET-1 is the most powerful endogenous vasoconstrictor of both small and large vessels $[34,35]$. It is a peptide with 21 amino acid residues and it is mostly released by endothelial cells of arteries, veins, and lymphatic vessels [36]. ET-1 acts as a modulator of the secretion of renin, vasopressin, and aldosterone, but at the same time it inhibits platelet aggregation [37]. Stressful conditions elicit increasing plasma levels of ET-1. Indeed, it has been observed in patients suffering with high blood pressure, arteriosclerosis, acute myocardial infarction, and diabetes mellitus [38-41]. Also hypoxic or oxidative stress, systemically and locally, has been identified as strong stimulus to raise primarily the levels 
of hypoxia-inducible factor 1 (HIF-1) and subsequently the levels of ET-1. In the eye, local synthesis and secretion of ET-1 are performed by many tissues, such as cornea, uveal tissue, retinal microvascular pericytes, RPE cells, and optic nerve, suggesting that the ET system could have an important role in the pathophysiology of some eye diseases [42-46]. Glaucoma, diabetic retinopathy, retinal vein/artery occlusion, proliferative vitreoretinopathy, and inherited retinal dystrophies are featured by impaired ocular blood circulation and they all present abnormal ET-1 plasma levels [47-51].

ET-2 is a protein encoded by the endothelin- 2 gene (EDN2) and is a member of the ET system. It is referred to as macrophage chemoattractant and it is strongly induced in PRs in the course of retinal diseases and injury, being involved as stress signal to Müller cells through $\mathrm{ET}_{\mathrm{B}}[52$, 53]. Supposedly, a wide range of retinal disorders, including the inherited retinal dystrophies such as RP, converge on a relatively small number of molecular pathways going towards the cellular repair or death [54]. Müller cells, the most abundant glial cells in the retina, seem to monitor the status of retinal neurons, being generally activated after PRs' degeneration or death $[55,56]$. There is evidence that injured or degenerated PRs start to release ET-2 stimulating the activation of the Müller cells fitted with $\mathrm{ET}_{\mathrm{B}}$. These glial cells increase both the production of glial fibrillary acidic protein and the sensitivity to ET-2 by upregulating the $\mathrm{ET}_{\mathrm{B}}$ as part of their repairing response $[53,57]$.

\section{ET-1 Blood Levels in Retinitis Pigmentosa}

ET-1 can be used as biochemical marker to assess ocular hemodynamics. To measure intraocular ET-1 blood concentration, colour Doppler imaging and laser Doppler flowmetry have been the two techniques specifically employed. Investigations showed the significant correlation between ET-1 plasma choroidal and plasma systemic concentrations [3]. In cases of RP, Cellini and coworkers have reported that a general increase in plasma levels of ET-1 elicits vasoconstriction both systemically and locally in the eye, causing retinal and choroidal hemodynamic impairment involving both ophthalmic artery and posterior ciliary arteries [2, 5, $6,58,59]$. The role of the ET system in the pathogenesis of several ocular diseases, including the RP, is unquestionably important. However, at present there are some discordant studies about ET-1 plasma levels in people suffering from inherited retinal dystrophies. Cellini and colleagues have repeatedly observed high concentrations of ET-1 in these patients, whereas Ohguro and colleagues reported low levels of ET-1 [3, 8, 51, 60]. Regardless of their opposite experimental observations, common evidence is the decreased intraocular blood flow, initially in both choroid and optic nerve head and later in retina, due to abnormal plasma levels of ET-1 $[61,62]$.

A proper biochemical pathway responsible for the reduced intraocular blood flow is still not ascertained; however, there are some hypotheses under investigation. The first is about the migration of RPE cells to the inner layers of the retina after PRs' death. Local secretion of ET-1 from the proliferated and migrated RPE cells may stimulate repairing processes by deposition of extracellular matrix
TABLE 1: The local and systemic increase of ET-1 and the vascular dysregulation syndrome in RP.

\begin{tabular}{|c|c|}
\hline \multirow{3}{*}{ Drop in ocular blood flow } & (i) Altered vessel caliber \\
\hline & (ii) Impaired vascular tone \\
\hline & (iii) Neurovascular coupling \\
\hline \multirow{4}{*}{ Drop in $\mathrm{O}_{2}$ retinal supply } & (i) Vasospasm \\
\hline & (ii) Ischemia \\
\hline & (iii) Hypoxia \\
\hline & $\begin{array}{l}\text { (iv) Biochemical and metabolic } \\
\text { alterations of retinochoroidal } \\
\text { endothelial cells }\end{array}$ \\
\hline \multirow{2}{*}{ Degeneration of PRs } & (i) Chronic oxidative stress \\
\hline & (ii) Subclinical inflammation \\
\hline
\end{tabular}

ET-1: endothelin-1; RP: retinitis pigmentosa; PRs: photoreceptors.

just underneath the retinal vessels [46]. As a consequence, thinning and fenestration of retinal vascular endothelial cells occur [63]. The second assumption considers the fact that the more the PRs die the less the ocular blood supply is required. Thus, a sort of vascular remodeling takes place in the chorioretinal tissue [64]. Another aspect to take into consideration is the low oxygen consumption by the degenerated and dying PRs. The subsequent vasoconstriction, mediated by increased levels of ET-1, is referred to as mechanism for limiting higher oxygen levels locally $[65,66]$. Table 1 supplies a brief and clear summary of the crucial role of ET-1 in RP.

On the basis of recent investigations, in subjects with RP there is a statistically significant correlation between the augmentation of ET-1 plasma levels and the drop of the peak systolic velocity in both the ophthalmic artery and the posterior ciliary arteries [51]. The genetics are definitely remarkable, but the impaired retinochoroidal blood supply might be considered as an important modifier of the progressive loss of PRs. Furthermore, a sort of systemic dysfunction of the microcirculation seems to be in people with RP. In fact, Cellini and coworkers have measured, by means of laser Doppler flowmetry, a lower baseline cutaneous capillary blood flow and a longer warm recovery time in RP patients with respect to healthy subjects [3]. It has been observed that biochemical and metabolic alterations of the endothelial cells of retinal vessels and the augmentation of the intraocular oxygen concentration are triggering factors for the retinal production of ET-1. This molecule provokes high levels of intracellular $\mathrm{Ca}^{2+}$ in glial and neuronal cells and increases both neuronal activities and neuronal responses to glutamate [67]. Also, through $\mathrm{ET}_{\mathrm{A}}$ receptors ET-1 may have a synergistic effect on the glutamate-induced neurotoxicity in the retina [68]. Other studies have also highlighted the pivotal role of ET-1 in relation to the apoptosis of the retinal ganglion cells through $\mathrm{ET}_{\mathrm{B}}$ receptors [69].

\section{Conclusions}

To date, big efforts are still to be made to assess a fine correlation between genetic mutations and clinical manifestations in the RP. The most of mutations occur in genes coding for 
proteins involved in the cycle of vision, at the level of rods, cones, and RPE cells [1]. In the course of the disease, the PRs go towards apoptosis, so that the outer retinal nuclear layer flattens [70]. The pigment deposits, described as bonespicule pigmentation, result from both RPE cell degeneration and migration into the neural retina after PRs' death [71]. There is evidence that oxidative stress and related conditions play an important role in the inherited retinal dystrophies [72]. Another important aspect of RP is the reduced blood flow in both ocular and peripheral districts along with a substantial increase in levels of inflammation $[1,22]$. Strobbe and coworkers demonstrated a statistically significant correlation between ocular inflammation, detected by measuring aqueous flare with the noninvasive laser flare-cell meter, and high ET-1 plasma levels in patients suffering from RP [60]. This condition features alterations in choroidal thickness and blood flow leading to a boost in free radicals and oxidative stress.

Several general conditions, such as hypoxia, chronic oxidative stress, vascular dysregulation, or systemic inflammation, provoke the increase of ET-1 plasma levels. This molecule acts as powerful vasoconstrictor resulting in drop of the blood flow. This aspect is well-recognized in patients with RP who have low and impaired ocular blood flow, also characterized by progressive choroidal thinning and attenuation of retinal vessels. Some authors have observed that RP subjects feature an imbalance of the antioxidant-oxidant status in the peripheral blood [73]. Thus, the subclinical general inflammation and the substantial oxidative stress trigger the production of high levels of ET-1, which in turn bring about vascular dysregulation and diffuse hypoxic stress. This vicious circle contributes to activating and amplifying the inflammatory response. In the eye, vasospasm and altered intraocular perfusion bring about relative ischemia and, as a consequence, degeneration of the PRs [60].

Further investigations are needed to confirm the link between vascular dysregulation and subclinical inflammation in RP. However, in the next future research probably focuses on the development of novel drugs as antagonists of ET-1 and new antioxidants in order to better improve the vascular function systemically as well as locally.

\section{Disclaimer}

The authors alone are responsible for the content and writing of this paper.

\section{Conflict of Interests}

The authors have no financial relationship with any organization.

\section{References}

[1] K. Konieczka, A. J. Flammer, M. Todorova, P. Meyer, and J. Flammer, "Retinitis pigmentosa and ocular blood flow," EPMA Journal, vol. 3, no. 1, article 17, 2012.

[2] J. E. Grunwald, A. M. Maguire, and J. Dupont, "Retinal hemodynamics in retinitis pigmentosa," American Journal of Ophthalmology, vol. 122, no. 4, pp. 502-508, 1996.
[3] M. Cellini, E. Strobbe, C. Gizzi, and E. C. Campos, "ET-1 plasma levels and ocular blood flow in retinitis pigmentosa," Canadian Journal of Physiology and Pharmacology, vol. 88, no. 6, pp. 630635, 2010.

[4] B. Falsini, G. M. Anselmi, D. Marangoni et al., "Subfoveal choroidal blood flow and central retinal function in retinitis pigmentosa," Investigative Ophthalmology \& Visual Science, vol. 52, no. 2, pp. 1064-1069, 2011.

[5] S. Wolf, H. Pöstgens, B. Bertram, K. Schulte, C. Teping, and M. Reim, "Hemodynamic findings of patients with retinitis pigmentosa," Klinische Monatsblätter für Augenheilkunde, vol. 199, no. 5, pp. 325-329, 1991.

[6] M. Cellini, L. Santiago, P. Versura, and R. Caramazza, "Plasma levels of endothelin-1 in retinitis pigmentosa," Ophthalmologica, vol. 216, no. 4, pp. 265-268, 2002.

[7] E. M. Vingolo, S. Lupo, P. L. Grenga et al., "Endothelin-1 plasma concentrations in patients with retinitis pigmentosa," Regulatory Peptides, vol. 160, no. 1-3, pp. 64-67, 2010.

[8] H. Ohguro, Y. Mashima, and M. Nakazawa, "Low levels of plasma endothelin-1 in patients with retinitis pigmentosa," Clinical Ophthalmology, vol. 4, no. 1, pp. 569-573, 2010.

[9] H. Saner, H. Würbel, F. Mahler, J. Flammer, and P. Gasser, "Microvasculatory evaluation of vasospastic syndromes," in Continuous Transcutaneous Monitoring, vol. 7 of Advances in Experimental Medicine and Biology, pp. 215-218, Springer, New York, NY, USA, 1987.

[10] U. Guthauser, J. Flammer, and F. Mahler, "The relationship between digital and ocular vasospasm," Graefe's Archive for Clinical and Experimental Ophthalmology, vol. 226, no. 3, pp. 224-226, 1988.

[11] F. Mahler, H. Saner, H. Würbel, and J. Flammer, "Local cooling test for clinical capillaroscopy in Raynaud's phenomenon, unstable angina, and vasospastic visual disorders," Vasa, vol. 18, no. 3, pp. 201-204, 1989.

[12] J. Flammer and M. Mozaffarieh, "Autoregulation, a balancing act between supply and demand," Canadian Journal of Ophthalmology, vol. 43, no. 3, pp. 317-321, 2008.

[13] D. Kavroulaki, K. Gugleta, A. Kochkorov, R. Katamay, J. Flammer, and S. Orgül, "Relation of body mass index and blood pressure to subjective and objective acral temperature," Klinische Monatsblatter fur Augenheilkunde, vol. 226, no. 4, pp. 328-331, 2009.

[14] M. Emre, S. Orgül, K. Gugleta, and J. Flammer, "Ocular blood flow alteration in glaucoma is related to systemic vascular dysregulation," British Journal of Ophthalmology, vol. 88, no. 5, pp. 662-666, 2004.

[15] K. Gugleta, C. Zawinka, I. Rickenbacher et al., "Analysis of retinal vasodilation after flicker light stimulation in relation to vasospastic propensity," Investigative Ophthalmology and Visual Science, vol. 47, no. 9, pp. 4034-4041, 2006.

[16] C. P. Hamel, "Retinitis pigmentosa," Orphanet Journal of Rare Diseases, vol. 1, article 40, 2006.

[17] A. T. Fahim, S. P. Daiger, and R. G. Weleber, "Retinitis pigmentosa overview," in GeneReviews, R. A. Pagon, M. P. Adam, H. H. Ardinger et al., Eds., University of Washington, Seattle, Wash, USA, 1993-2015.

[18] S. Ferrari, E. Di Iorio, V. Barbaro, D. Ponzin, F. S. Sorrentino, and F. Parmeggiani, "Retinitis pigmentosa: genes and disease mechanisms," Current Genomics, vol. 12, no. 4, pp. 238-249, 2011.

[19] F. Parmeggiani, "Clinics, epidemiology and genetics of retinitis pigmentosa," Current Genomics, vol. 12, no. 4, pp. 236-237, 2011. 
[20] S. P. Daiger, L. S. Sullivan, and S. J. Bowne, "Genes and mutations causing retinitis pigmentosa," Clinical Genetics, vol. 84, no. 2, pp. 132-141, 2013.

[21] J. Flammer, M. Pache, and T. Resink, "Vasospasm, its role in the pathogenesis of diseases with particular reference to the eye," Progress in Retinal and Eye Research, vol. 20, no. 3, pp. 319-349, 2001.

[22] J. Flammer, K. Konieczka, and A. J. Flammer, "The primary vascular dysregulation syndrome: implications for eye diseases," EPMA Journal, vol. 4, no. 1, article 14, 2013.

[23] V. A. Convertino, "Neurohumoral mechanisms associated with orthostasis: reaffirmation of the significant contribution of the heart rate response," Frontiers in Physiology, vol. 5, article 236, 2014.

[24] I. O. Haefliger, P. Meyer, J. Flammer, and T. F. Lüscher, "The vascular endothelium as a regulator of the ocular circulation: a new concept in ophthalmology?" Survey of Ophthalmology, vol. 39, no. 2, pp. 123-132, 1994.

[25] I. O. Haefliger, J. Flammer, J.-L. Bény, and T. F. Lüscher, "Endothelium-dependent vasoactive modulation in the ophthalmic circulation," Progress in Retinal and Eye Research, vol. 20, no. 2, pp. 209-225, 2001.

[26] J. Flammer and M. Mozaffarieh, "Autoregulation, a balancing act between supply and demand," Canadian Journal of Ophthalmology, vol. 43, no. 3, pp. 317-321, 2008.

[27] W. Neuhuber and F. Schrödl, "Autonomic control of the eye and the iris," Autonomic Neuroscience: Basic and Clinical, vol. 165, no. 1, pp. 67-79, 2011.

[28] R. M. Kedzierski and M. Yanagisawa, "Endothelin system: the double-edged sword in health and disease," Annual Review of Pharmacology and Toxicology, vol. 41, pp. 851-876, 2001.

[29] D. E. Clouthier, K. Hosoda, J. A. Richardson et al., "Cranial and cardiac neural crest defects in endothelin-A receptor-deficient mice," Development, vol. 125, no. 5, pp. 813-824, 1998.

[30] A. G. Baynash, K. Hosoda, A. Giaid et al., "Interaction of endothelin-3 with endothelin-B receptor is essential for development of epidermal melanocytes and enteric neurons," Cell, vol. 79, no. 7, pp. 1277-1285, 1994.

[31] K. Hosoda, R. E. Hammer, J. A. Richardson et al., "Targeted and natural (piebald-lethal) mutations of endothelin-B receptor gene produce megacolon associated with spotted coat color in mice," Cell, vol. 79, no. 7, pp. 1267-1276, 1994.

[32] M. Bianchi, J. Adur, S. Takizawa, K. Saida, and V. H. Casco, "Endothelin system in intestinal villi: a possible role of endothelin-2/vasoactive intestinal contractor in the maintenance of intestinal architecture," Biochemical and Biophysical Research Communications, vol. 417, no. 4, pp. 1113-1118, 2012.

[33] A. N. Bramall, M. J. Szego, L. R. Pacione et al., "Endothelin2-mediated protection of mutant photoreceptors in inherited photoreceptor degeneration," PLoS ONE, vol. 8, no. 2, Article ID e58023, 2013.

[34] M. Yanagisawa, H. Kurihara, S. Kimura et al., "A novel potent vasoconstrictor peptide produced by vascular endothelial cells," Nature, vol. 332, no. 6163, pp. 411-415, 1988.

[35] T. Masaki, S. Kimura, M. Yanagisawa, and K. Goto, "Molecular and cellular mechanism of endothelin regulation: implications for vascular function," Circulation, vol. 84, no. 4, pp. 1457-1468, 1991.

[36] J. R. Vane, R. Botting, and T. Masaki, "Endothelin," Journal of Cardiovascular Pharmacology, vol. 13, supplement 5, pp. S1-S23, 1989.
[37] M. S. Simonson and M. J. Dunn, "Cellular signaling by peptides of the endothelin gene family," The FASEB Journal, vol. 4, no. 12, pp. 2989-3000, 1990.

[38] T. Miyauchi, M. Yanagisawa, T. Tomizawa et al., "Increased plasma concentrations of endothelin-1 and big endothelin-1 in acute myocardial infarction," The Lancet, vol. 334, no. 8653, pp. 53-54, 1989.

[39] K. Takahashi, M. A. Ghatei, H.-C. Lam, D. J. O’Halloran, and S. R. Bloom, "Elevated plasma endothelin in patients with diabetes mellitus," Diabetologia, vol. 33, no. 5, pp. 306-310, 1990.

[40] M. Kohno, K. Yasunari, K.-I. Murakawa et al., "Plasma immunoreactive endothelin in essential hypertension," The American Journal of Medicine, vol. 88, no. 6, pp. 614-618, 1990.

[41] A. Lerman, B. S. Edwards, J. W. Hallett, D. M. Heublein, S. M. Sandberg, and J. C. Burnett Jr., "Circulating and tissue endothelin immunoreactivity in advanced atherosclerosis," The New England Journal of Medicine, vol. 325, no. 14, pp. 997-1001, 1991.

[42] M. W. MacCumber, H. D. Jampel, and S. H. Snyder, "Ocular effects of the endothelins: abundant peptides in the eye," Archives of Ophthalmology, vol. 109, no. 5, pp. 705-709, 1991.

[43] E. Granstam, L. Wang, and A. Bill, "Ocular effects of endothelin1 in the cat," Current Eye Research, vol. 11, no. 4, pp. 325-332, 1992.

[44] P. Chollet, F. Malecaze, L. Gouzi, J. L. Arne, and J. Plouet, "Endothelin 1 is a growth factor for corneal endothelium," Experimental Eye Research, vol. 57, no. 5, pp. 595-600, 1993.

[45] A. Ripodas, J. A. de Juan, M. Roldán-Pallarés et al., "Localisation of endothelin-1 mRNA expression and immunoreactivity in the retina and optic nerve from human and porcine eye. Evidence for endothelin-1 expression in astrocytes," Brain Research, vol. 912, no. 2, pp. 137-143, 2001.

[46] S. Narayan, A. M. Brun, and T. Yorio, "Endothelin-1 distribution and basolateral secretion in the retinal pigment epithelium," Experimental Eye Research, vol. 79, no. 1, pp. 11-19, 2004.

[47] H. J. Kaiser, J. Flammer, M. Wenk, and T. Luscher, "Endothelin-1 plasma levels in normal-tension glaucoma. Abnormal response to postural changes," Graefe's Archive for Clinical and Experimental Ophthalmology, vol. 233, no. 8, pp. 484-488, 1995.

[48] H. Oku, T. Kida, T. Sugiyama, J. Hamada, B. Sato, and T. Ikeda, "Possible involvement of endothelin-1 and nitric oxide in the pathogenesis of proliferative diabetic retinopathy," Retina, vol. 21, no. 6, pp. 647-651, 2001.

[49] M. Roldán-Pallarés, R. Rollín, A. Mediero et al., "Immunoreactive ET-1 in the vitreous humor and epiretinal membranes of patients with proliferative vitreoretinopathy," Molecular Vision, vol. 11, pp. 461-471, 2005.

[50] I. Ohguro, H. Ohguro, H. Ohkuro, and M. Nakazawa, "Study of contribution of low level of plasma endothelin-1 concentration to pathogenesis of glaucomatous optic neuropathy," Hirosaki Medical Journal, vol. 57, no. 2-4, pp. 59-64, 2006.

[51] A. Finzi, M. Cellini, E. Strobbe, and E. C. Campos, "ET-1 plasma levels, choroidal thickness and multifocal electroretinogram in retinitis pigmentosa," Life Sciences, vol. 118, no. 2, pp. 386-390, 2014.

[52] M. J. Grimshaw, J. L. Wilson, and F. R. Balkwill, "Endothelin-2 is a macrophage chemoattractant: implications for macrophage distribution in tumors," European Journal of Immunology, vol. 32, no. 9, pp. 2393-2400, 2002.

[53] A. Rattner and J. Nathans, "The genomic response to retinal disease and injury: evidence for endothelin signaling from 
photoreceptors to glia," Journal of Neuroscience, vol. 25, no. 18, pp. 4540-4549, 2005.

[54] L. R. Pacione, M. J. Szego, S. Ikeda, P. M. Nishina, and R. R. McInnes, "Progress toward understanding the genetic and biochemical mechanisms of inherited photoreceptor degenerations," Annual Review of Neuroscience, vol. 26, pp. 657-700, 2003.

[55] A. Bringmann and A. Reichenbach, "Role of Muller cells in retinal degenerations," Frontiers in Bioscience, vol. 6, pp. e72-92, 2001.

[56] M. García and E. Vecino, "Role of Müller glia in neuroprotection and regeneration in the retina," Histology and Histopathology, vol. 18, no. 4, pp. 1205-1218, 2003.

[57] G. P. Lewis and S. K. Fisher, "Up-regulation of glial fibrillary acidic protein in response to retinal injury: its potential role in glial remodeling and a comparison to vimentin expression," International Review of Cytology, vol. 230, pp. 263-290, 2003.

[58] C. Ulrich, W.-D. Ulrich, K. Vehlow, and S. Vehlow, "Hemodynamic aspects of retinitis pigmentosa," Fortschritte der Ophthalmologie, vol. 88, no. 6, pp. 642-647, 1991.

[59] M. Cellini, R. Lodi, G. L. Possati, M. Sbrocca, D. Pelle, and N. Giubilei, "Color Doppler ultrasonography in retinitis pigmentosa: preliminary study," Journal Français d'Ophtalmologie, vol. 20, no. 9, pp. 659-663, 1997.

[60] E. Strobbe, M. Cellini, M. Fresina, and E. C. Campos, "ET-1 plasma levels, aqueous flare, and choroidal thickness in patients with retinitis pigmentosa," Journal of Ophthalmology, vol. 2015, Article ID 292615, 6 pages, 2015.

[61] K. Polak, V. Petternel, A. Luksch et al., "Effect of endothelin and BQ123 on ocular blood flow parameters in healthy subjects," Investigative Ophthalmology \& Visual Science, vol. 42, no. 12, pp. 2949-2956, 2001.

[62] K. Polak, A. Luksch, B. Frank, K. Jandrasits, E. Polska, and L. Schmetterer, "Regulation of human retinal blood flow by endothelin-1," Experimental Eye Research, vol. 76, no. 5, pp. 633640, 2003.

[63] D. T. Hartong, E. L. Berson, and T. P. Dryja, "Retinitis pigmentosa," The Lancet, vol. 368, no. 9549, pp. 1795-1809, 2006.

[64] J. L. Stone, W. E. Barlow, M. S. Humayun, E. De Juan Jr., and A. H. Milam, "Morphometric analysis of macular photoreceptors and ganglion cells in retinas with retinitis pigmentosa," Archives of Ophthalmology, vol. 110, no. 11, pp. 1634-1639, 1992.

[65] C. J. Pournaras, C. E. Riva, M. Tsacopoulos, and K. Strommer, "Diffusion of $\mathrm{O}_{2}$ in the retina of anesthetized miniature pigs in normoxia and hyperoxia," Experimental Eye Research, vol. 49, no. 3, pp. 347-360, 1989.

[66] S. Dallinger, G. T. Dorner, R. Wenzel et al., "Endothelin1 contributes to hyperoxia-induced vasoconstriction in the human retina," Investigative Ophthalmology and Visual Science, vol. 41, no. 3, pp. 864-869, 2000.

[67] M. Shihara, Y. Hirooka, N. Hori et al., "Endothelin-1 increases the neuronal activity and augments the responses to glutamate in the NTS," The American Journal of Physiology-Regulatory Integrative and Comparative Physiology, vol. 275, no. 2, pp. R658-R665, 1998.

[68] T. Kobayashi, H. Oku, M. Fukuhara et al., "Endothelin1 enhances glutamate-induced retinal cell death, possibly through ETA receptors," Investigative Ophthalmology \& Visual Science, vol. 46, no. 12, pp. 4684-4690, 2005.
[69] R. R. Krishnamoorthy, V. R. Rao, R. Dauphin, G. Prasanna, C. Johnson, and T. Yorio, "Role of the $\mathrm{ET}_{\mathrm{B}}$ receptor in retinal ganglion cell death in glaucoma," Canadian Journal of Physiology and Pharmacology, vol. 86, no. 6, pp. 380-393, 2008.

[70] V. Marigo, "Programmed cell death in retinal degeneration: targeting apoptosis in photoreceptors as potential therapy for retinal degeneration," Cell Cycle, vol. 6, no. 6, pp. 652-655, 2007.

[71] Z.-Y. Li, D. E. Possin, and A. H. Milam, "Histopathology of bone spicule pigmentation in retinitis pigmentosa," Ophthalmology, vol. 102, no. 5, pp. 805-816, 1995.

[72] K. Komeima, B. S. Rogers, and P. A. Campochiaro, "Antioxidants slow photoreceptor cell death in mouse models of retinitis pigmentosa," Journal of Cellular Physiology, vol. 213, no. 3, pp. 809-815, 2007.

[73] C. Martínez-Fernández de la Cámara, D. Salom, M. D. Sequedo et al., "Altered antioxidant-oxidant status in the aqueous humor and peripheral blood of patients with retinitis pigmentosa," PLoS ONE, vol. 8, no. 9, Article ID e74223, 2013. 


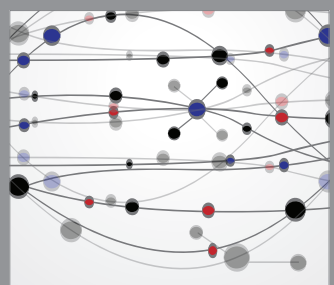

The Scientific World Journal
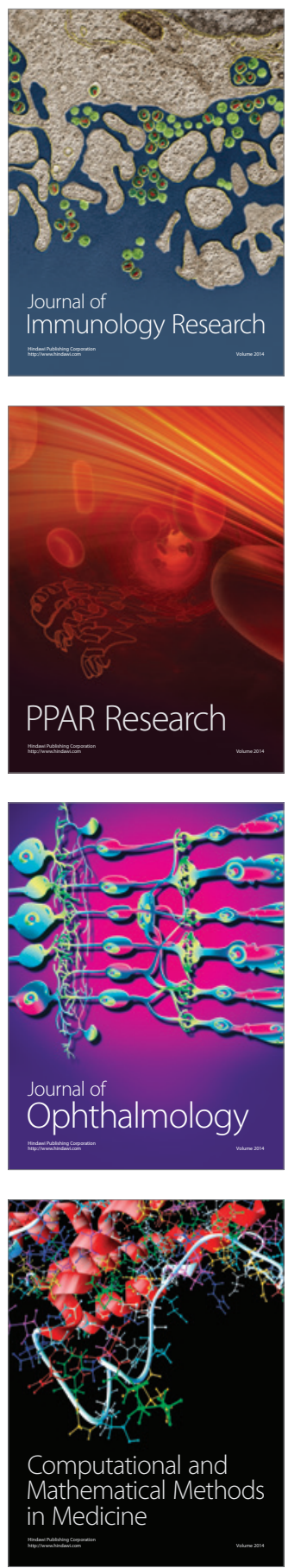

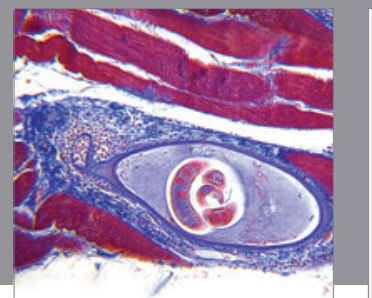

Gastroenterology

Research and Practice
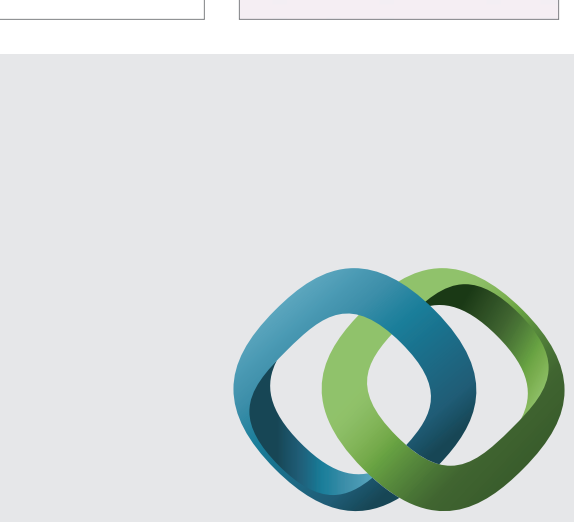

\section{Hindawi}

Submit your manuscripts at

http://www.hindawi.com
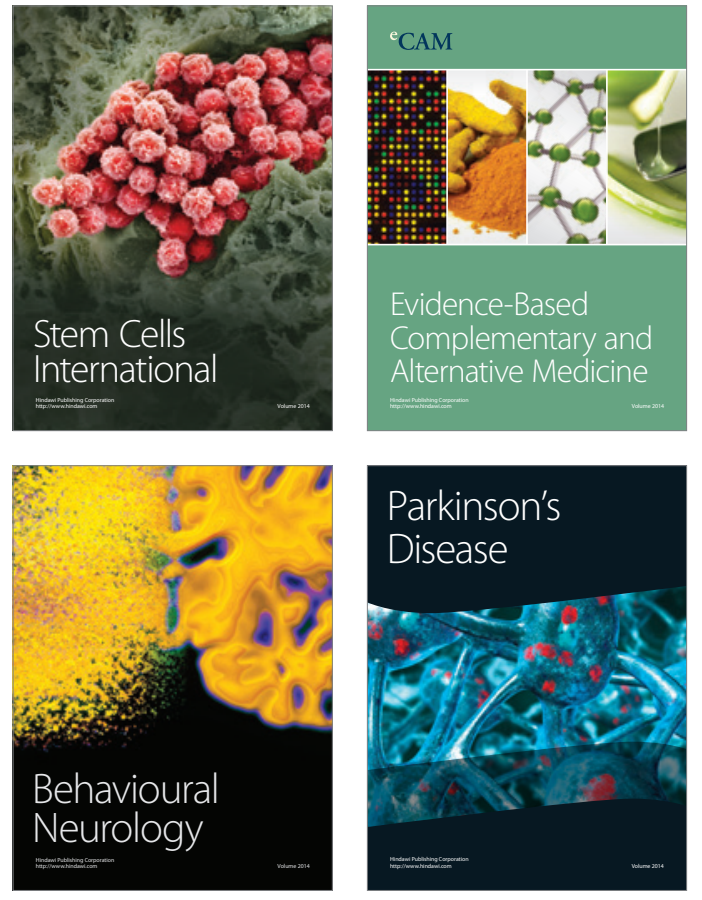
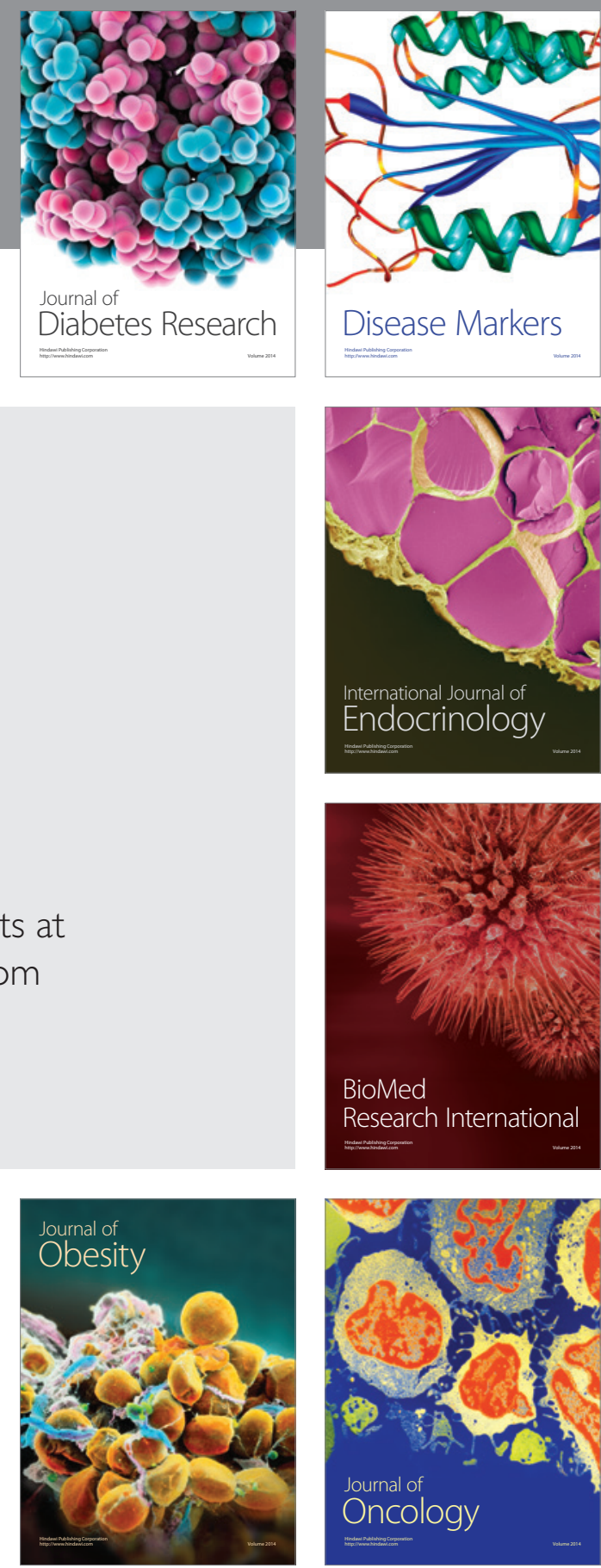

Disease Markers
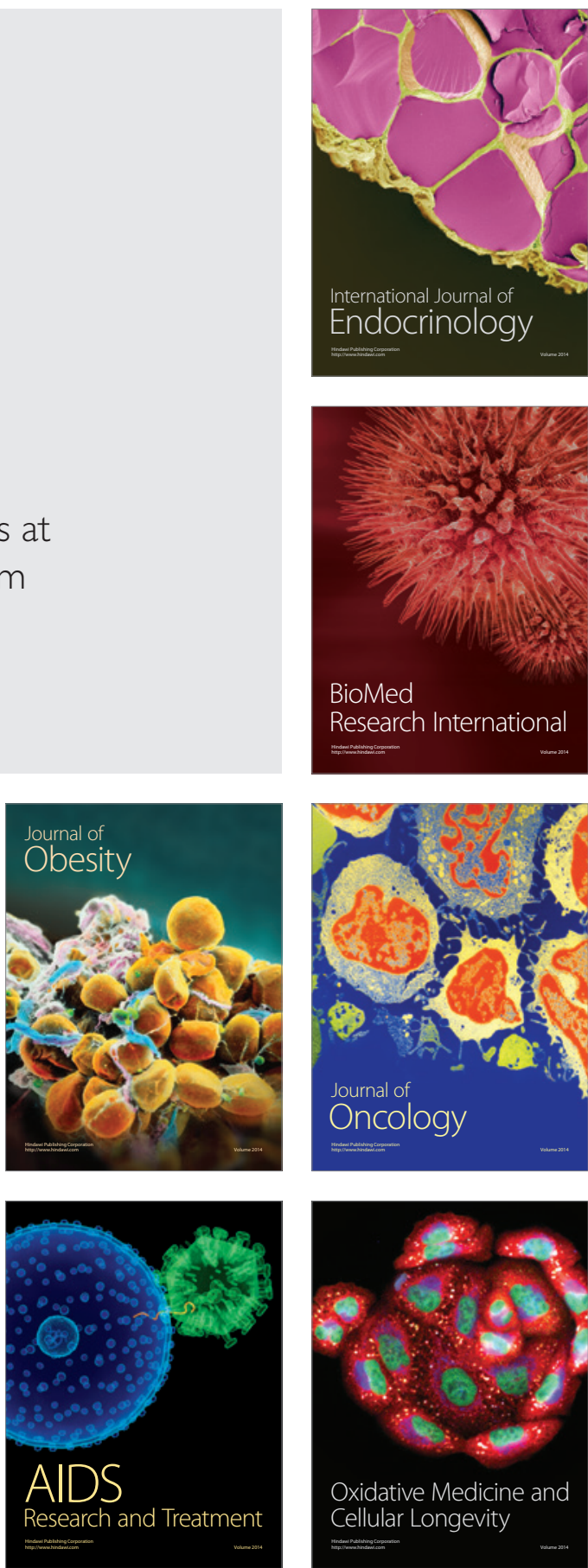